\title{
Conceptualising the Benefit Framework of an Enterprise Content Management System (ECMS)
}

\author{
Mohamad Rahimi Mohamad Rosman ${ }^{1}$, and Mohammad Azhan Abdul Aziz ${ }^{2}$ \\ ${ }^{1}$ Department of Information System Management, Faculty of Information Management, \\ Universiti Teknologi MARA, 18500 Machang, Kelantan, Malaysia \\ ${ }^{2}$ Faculty of Information Management, Universiti Teknologi MARA, \\ 08400 Merbok, Kedah, Malaysia \\ ${ }^{1}$ E-mail: rahimimr@kelantan.uitm.edu.my
}

Received: 10 October 2018

Accepted: 30 October 2018

\section{ABSTRACT}

Content management is an organisational effort of managing content, particularly in digital format. Although it has been over 25 years since content management was introduced, this field of study is still considered an emerging topic with unresolved issues-in particular, the subject of benefit achievement. Therefore, grounded on an extensive review of 135 articles, the purpose of this study is to investigate the benefits that organisations can gain through the proper use of an Enterprise Content Management System (ECMS). Subsequently, this paper identifies a list of ECMS benefits and proposes an ECMS benefit framework for further exploration into this field. Our result shows that although ECMS does bring benefits to organisations, these benefits are diverse; indicating that there are certain determinants or factors influencing the achievement of such benefits. Moreover, it is also found that in the context of the benefit framework of Shang and Seddon [10], three categories were found relevant to the field of content management: operational benefit, managerial benefit, and strategic benefit.

Keywords: content management, enterprise content management, enterprise content management system, benefit realisation, economics of $I S$, enterprise systems. 


\section{INTRODUCTION}

Organisations nowadays are experiencing a crucial phenomenon known as 'content chaos'. A large volume of content has been created that are now out of the control of normal organisational practices. As a result, employees waste precious time searching for relevant information. The International Data Corporation (IDC) reported that 74 percent of organisational content is unstructured, and it is predicted that more than 80 percent (approximately 133 Exabytes) of organisational content would become unstructured by 2017 [1]. Gaining access to unstructured content has caused retrieval and utilisation challenges for organisations [2].

Thus, organisations are in need of a concept and tool for content management. To address this demand, an Enterprise Content Management System (ECMS) was introduced in 2001. The Association for Information and Image Management (AIIM) defines ECMS as the strategies, methods, and tools used to capture, manage, store, preserve, and deliver content and documents related to organisational processes [3].

Although ECMS was introduced 14 years ago, there seems to be a lack of enterprise-wide implementation in modern organisations [4]. Reports of failure cases when implementing ECMS may have discouraged organisations from adopting ECMS [5]. Moreover, an extensive literature review has shown that organisations adopted ECMS because of vendor influences [6-7] and unproven claims of ECMS benefits [7-9].

Currently, business and IT managers are taking precautions in implementing ECMS due to their uncertainty of the benefits of ECMS [9]. Thus, there is a need to study the benefits that organisations can gain from the use of ECMS. Therefore, the following research question is posed:

\section{What are the benefits that an organisation can gain by implementing ECMS?}

Grounded on an extensive review of 135 articles, there are three main contributions of this paper. Firstly, the benefits of ECMS were identified. Secondly, an ECMS benefit framework was proposed based on the benefit 
framework of Shang and Seddon [10]. Thirdly, the future direction of this research was outlined to add new knowledge to the field.

The rest of this paper is organised as follows: the next section provides a brief literature review on the research into ECMS benefits. Then, the benefits identified from the literature are categorised based on the benefit framework of Shang and Seddon [10]. Next, findings on the ECMS benefits are summarised and future directions and further exploration into this topic discussed. Finally, the paper is concluded, and limitations of the study outlined.

\section{LITERATURE REVIEW}

Organisations view content as an asset that can drive productivity [11]. Content includes any type of unstructured, semi-structured, or structured digital information, such as images, graphics, videos, sounds, documents or records that are likely to be stored and managed in electronic format [12]. As content gradually increases over the years, organisations find themselves faced with a crucial phenomenon known as 'content chaos' [13-14]. Therefore, content management has been introduced to help organisations manage their organisational content. Boiko [15] defines content management as, 'a process of collecting, managing, and publishing content'. This process involves several activities such as version control, access, and content reuse.

Content management helps organisations reduce operating cost [1617]. For example, Scott [18] reported that J.D Edwards achieved 1811\% return-of-investment due to cost-savings in printing and when searching for appropriate information. A-Dec Inc. reported savings of $\$ 13,000$ for two document types by reusing the same document and minimising the services of content creators and content auditors [19].

However, although content management was introduced in the $1980 \mathrm{~s}$, it is still considered an emerging concept and still has some unresolved issues, particularly relating to benefit achievement [2][20-22]. It seems that organisations are now making huge investments in ECMS technologies, yet there are contradictory responses between ECMS vendors, academics, 
and practitioners [23]. ECMS vendors, through a series of published case studies, have shown the benefits of ECMS implementation such as the facilitation of information sharing, cost reduction, improved collaboration, and enhanced strategic decision-making. Yet, the voices of academics and practitioners seem to contradict with the view of ECMS vendors. Academics and practitioners argue that organisations are struggling to realise the benefits of ECMS implementation [2][7][20-21]. Based on a market analysis spanning more than 20 years, the failure rate of ECMS implementation sits at a staggering $50 \%$ and only half of the remaining $50 \%$ had actually provided value to organisations [24]. This statistic supports the claims of academics that there is lack of evidence that ECMS has contributed to the improvement of business processes and organisational efficiency [2][7].

Several researches concerning ECMS benefits have been conducted [2][5][21][24]. For example, Paivarinta and Munkvold [21] introduced a widely accepted major ECMS issue framework. The authors suggested that implementation of the ECM system should support the objective (benefits desired) and desired enterprise model (process-based, team-based or projectbased, etc.). Organisations implement the ECM system to fulfill their specific objective. The authors claim that implementation based on objectives will produce the anticipated and desired impacts. On the other hand, Rickenberg, Neumann, Hohler, and Breitner [24] developed an extended framework in their research on ECM. They identified several ECMS benefits: cost and efficiency, compliance and security, continuity, consolidation and integration, collaboration and customer service. The authors acknowledge that the ECMS literature has mainly dealt with constructive studies, conceptual ideas and frameworks, and technological functionalities. The authors therefore suggest the need for more fundamental research to add to the knowledge on ECMS. Future research should also consider other ECMS benefits such as consistency, content quality, and content intelligence.

Based on an analysis of previous studies, it is found that these studies had generalised benefits into a single construct. For example, Grahlmann, Hilhorst, Van Amerongen, Helms, and Brinkkemper [25] described ECMS benefits as the potential impacts of implementing ECMS. From the perspective of ERP, researchers would generalise benefits as the postimplementation success of ERP [26], benefits realised [27], local (plant)level overall benefits [9], ERP implementation success [29], organisational 
benefits from system use (from the perspective of senior management) [30], and business benefits from ERP system use [31].

Based on previous research, several issues are highlighted. First, there is no specific mention on how organisations gain benefits from using ECMS and the factors that drive the achievement of these benefits. Second, the authors did not identify the benefits that are the main drivers of ECMS implementation. The third issue is the use of secondary data that certainly favours ECMS vendors. Another issue centers around the lack of a benefit framework to further enhance the knowledge on ECMS benefits other than the work of Grahlmann, Hilhorst, Van Amerongen, Helms, and Brinkkemper [25]. Besides that, there is also an inadequate relationship between benefit drivers and benefit achievement. Previous researchers did not mention the type of driver and the resulting type of benefits that would be achieved. Due to some limitations of this paper, focus was kept only on the types of benefits that organisations could gain through the proper use of ECMS applications. Other issues surrounding the determinants of ECMS benefits will be discussed elsewhere.

In order to determine the benefits that organisations can gain from ECMS, this study adopted the benefits framework of Shang and Seddon [10], to classify the benefits into categories. The next section describes the proposed ECMS benefit framework.

\section{ECMS BENEFIT FRAMEWORK}

In order to guide the development of the benefit framework, this research adopted the benefit framework of Shang and Seddon [10]. This framework classifies benefits into five categories: operational, managerial, strategic, IT infrastructure, and organisational. Operational benefits are concerned with the reduction of cost and improvement of productivity, quality, and customer service. Managerial benefits refer to performance improvement, better resource management, and improvement of the decision-making process. On the other hand, strategic benefits are concerned with business growth and alliance, innovation, product differentiation, and building 
external linkages. IT infrastructure, meanwhile, supports business flexibility, IT cost reduction, and increased IT infrastructure capability. Organisational benefits are concerned with business process reengineering, organisational learning, empowerment, and building a common vision.

In order to identify the list of benefits of ECMS, a structured and systematic literature search based on the approach of Webster and Watson [56] was adopted. Webster and Watson [56] suggested that: (1) the literature search must begin with leading journals; (2) a backward search must be done to consider all relevant literature; and (3) a forward search performed to determine citing articles.

A three-phase process was conducted in this study. The first phase involved a search for all relevant articles related to ECM in which the following tools were used: Google Scholar, Science Direct, IEEE Xplore, Emerald, Proquest Central, Scopus, and Discovery. The keywords used are 'enterprise content management' and 'enterprise content management system'. A total of 1148 publications were identified. These were then trimmed to 563 publications using the 'Find Duplicates' function in EndNote $\mathrm{X} 7$. Later, manual checking was performed to remove other duplications and irrelevant articles. Finally, 172 papers were selected for the secondphase filtering. In the second phase, the publications were screened based on: (1) relevance of the study to ECM; (2) the quality of the publication; and (3) publication contribution. The papers were read through diligently based on the approaches of Glaser and Strauss [57]. Finally, 135 papers were selected for the reviewing process.

This study classified ECMS benefits into three categories: strategic, operational, and managerial. IT infrastructure and organisational benefits were not seen as important because: (1) the use of ECMS involves less engineering work processes [20] [22] [32], and (2) technology is not considered an important driver for ECMS adoption [24][33-34]. The following table 1 shows the proposed ECMS benefit framework: 
Table:1. ECMS Benefits Framework

\begin{tabular}{|c|c|c|}
\hline Category & Benefits & Selected Literature \\
\hline \multirow{6}{*}{ Operational } & Cost reduction & $\begin{array}{l}{[16][21[24][37][38][40][44]} \\
{[48][55]}\end{array}$ \\
\hline & $\begin{array}{l}\text { Facilitate information } \\
\text { sharing }\end{array}$ & {$[20][21][22][40]$} \\
\hline & $\begin{array}{l}\text { Improved search and } \\
\text { retrieval }\end{array}$ & [22] [32] [46] [47] [51] [52] [55] \\
\hline & Task efficiency & {$[5][16][20][21][24][38][46][48]$} \\
\hline & Integration & {$[22][24][32][40][41][43][44][49]$} \\
\hline & Customisation & [22] [37] [43] [54] \\
\hline \multirow[t]{3}{*}{ Managerial } & $\begin{array}{l}\text { Improved decision- } \\
\text { making }\end{array}$ & $\begin{array}{l}{[5][16][21][20][24][35][38][46]} \\
{[48]}\end{array}$ \\
\hline & $\begin{array}{l}\text { Governance and } \\
\text { compliance }\end{array}$ & $\begin{array}{l}{[5][7][21][22][24][28][32][36]} \\
{[38][41]}\end{array}$ \\
\hline & Information quality & $\begin{array}{l}{[21][22][24][32][38][39][42]} \\
{[52][53]}\end{array}$ \\
\hline \multirow[t]{2}{*}{ Strategic } & Collaboration & [20] [21] [22] [32] [38] [46] [49] \\
\hline & Continuity & [5] [24] [40] [44] \\
\hline
\end{tabular}

\section{FINDINGS SUMMARY}

In summary, we found that the benefit framework of Shang and Seddon [10] is sufficient and comprehensive enough to explain the focus of ECMS benefits. The subsequent section explains each benefit identified from the literature search.

\section{OPERATIONAL BENEFITS}

Operational benefits are day-to-day activities that involve acquiring and utilising resources. The activities are usually repeated periodically on a daily, weekly, or monthly basis [10]. The six benefits under operational benefits are: 


\section{Cost reduction}

ECMS allows the reduction of operational costs, facility costs, and production costs [16][21]. For example, J.D. Edwards reported 1811\% return-of-investment (ROI) in time saving during information searching and reduced printing cost [21]. A-Dec Inc. saved \$13, 000 through content reuse and minimising the services of content auditors and content creators [19].

\section{Facilitate information sharing}

ECMS enables information flow throughout the organisation. Information sharing improves knowledge creation [21]. Information sharing enables improved task efficiency [40] and reduces production cost [19].

\section{Improved search and retrieval}

The existence of unstructured content reduces the search and retrieval capability of employees, who could waste $30 \%$ of their time searching for relevant and current versions of content. Improving the search and retrieval function enables greater information sharing and reuse [26].

\section{Task efficiency}

ECMS allows work to be accomplished with minimum resource utilisation and reduced processing time [5]. Employees can save time when searching for relevant information, which would allow collaborative work and information sharing [21-22][32]. For example, ECMS allows the reuse of previously created content, documents, and templates [16][19].

\section{Integration}

Integration allows content sharing and access throughout the organisation [34]. For example, removal of content silos and inefficient business processes through integration will help improve organisational performance and productivity [32]. 


\section{Customisation}

Nordheim and Paivarinta [37] suggested that the customisation offered by ECMS has influenced organisations to implement the system. Customisation allows improved functionality in meeting organisational needs and contributes towards cost reduction [31].

\section{MANAGERIAL BENEFITS}

Managerial benefits involve utilisation, control, and monitoring of a firm's resources and operations that usually rely on summarised information or excerpts from reports [10]. Three benefits identified under this category are:

\section{Improved decision-making}

ECMS allows organisations to improve the quality of decision-making by providing managers with more information and insight into company data [29]. For example, ECMS allows access to previously unstructured content.

\section{Governance and compliance}

Meeting governance and compliance regulations, such as the SarbanesOxley Act (2002), is among the major benefits organisations seek to achieve from using ECMS. For example, in Malaysia, organisations are bound to the Electronic Records and Archival Act (2003) when managing digital content. The need to address external regulations and standards has influenced organisations to use ECMS [21].

\section{Information quality}

Access to information quality helps organisations make strategic and accurate decision-making. Information quality provides real-time information to support current and future needs [32], as well as enables the creation and production of newly added services or customer services [21]. 


\section{STRATEGIC BENEFITS}

ECMS helps organisations to leverage value from their information asset. Strategic benefits involve long-term planning, particularly at the high-level decision-making phase such as business growth, alliance, innovation, cost, differentiation, and external linkages [10]. Two important benefits from the ECMS strategic perspective are:

\section{Collaboration}

ECMS allows business processing between and within departments through a collaborative process. Collaboration and integration have a causal effect. The integration of separate business processes allows collaborative work. Collaboration increases task efficiency [40] and reduces operational costs [22]. Collaboration also improves an organisation's resource utilisation[21] and facilitates information sharing [20].

\section{Continuity}

Continuity is an organisation's capability to survive challenges to maintain their existence or relevance. ECMS supports organisational growth and business alliance by providing a specific mechanism for identifying and justifying investment into the system [34]. Organisations should view ECMS as part of their disaster recovery planning approach [5].

\section{DISCUSSION}

Based on the selected studies, several issues are highlighted. First, although numerous studies have acknowledged the positive impact of ECMS, it is worth noting that these studies used secondary data as evidence [2][21][24]. Therefore, there is a need to further investigate the accuracy of these claims beyond what researchers and practitioners call 'vendor promises' [6][7].

Second, underneath these proclaimed benefits, researchers argue that ECMS is actually underutilised and is not aligned with the way businesses work [20-22]. Consequently, organisations struggle to realise the benefits 
of ECMS implementation [2][7][20][22] and have difficulty justifying their investment in ECMS due to a lack of knowledge of ECMS benefits [2][22]. Studying the pathway of benefit achievement will therefore help organisations to understand why certain benefits may or may not occur [9].

Third, it is suggested that researchers shift their focus towards the people aspect of ECM research. There is a compelling need to expand on the knowledge of the impact of ECM on employees-either improvement of skills or deskilling-due to technicality of information. Moreover, the role of a 'project champion' could also become one possible research area.

\section{CONCLUSION}

In this paper, a list of ECMS benefits grounded on an extensive review of 135 articles was provided. Then, an ECMS benefit framework based on the framework of Shang and Seddon [10] was proposed. Each benefit was classified into three categories: operational benefits, managerial benefits, and strategic benefits. Finally, each benefit was delineated and the paper concluded with an outline of potential future studies.

This study is not without limitations. First, the majority of studies that was identified showed a lack of empirical evidences and depended on vendor reports. Although these could be trusted, such evidences may be biased towards the software vendors. Second, there were only a few academic reports on actual ECMS practices. This lack of actual evidence of ECMS benefits may lead to biased and inaccurate benefit claims. Third, although it is claimed that this paper is grounded on extensive literature reviews, it is still possible that some papers had been unintentionally left out from the review. However, it is believed that this paper provides more comprehensive information than previous works in the field.

A further study will be carried out with a focus on investigating the determinants that contribute to the achievement of ECMS benefits. Since there is solid evidence that ECMS benefits are difficult to gain [2][7][16] [20][22], studying the pathway of benefit achievement may provide new knowledge as to why benefits may or may not occur [9]. 


\section{REFERENCES}

[1] A. Nadkarni, and N. Yezhkova, 2014. Structured Versus Unstructured Data: The Balance of Power Continues to Shift. Industry Development and Models

[2] L. T. P. Salamntu, and L. F. Seymour, 2014. A Review of Organisational Benefits Through the Use of Enterprise Content Management (ECM) System in Public Sector Organisations. In Third International Conference on Informatics Engineering and Information Science (ICIEIS 2014), Lodz, Poland, Sept 22-24, 2014.

[3] Association for Information and Image Management, 2017. What is Enterprise Content Management (ECM)?. Retrieved from http://www. aiim.org/What-is-ECM-Enterprise-Content-Management.

[4] D. Miles, 2010. State of the ECM Industry 2011: How well is it meeting business needs? Received https://www.aiim.org/pdfdocuments/ECMState-of-Industry-2011.pdf.

[5] R. Kunstová, 2010. Barriers and benefits of investments into enterprise content management systems, Organizacija, Vol. 43(5), pp. 205-213.

[6] C. Riley, 2014. Why I Left ECM. Retrieved from http://www. hoardinginformation.com/why-i-left-ecm/.

[7] R. Andersen, 2007. The rhetoric of enterprise content management (ECM): Confronting the assumptions driving ECM adoption and transforming technical communication, Technical Communication Quarterly, Vol. 17(1). DOI: 10.1080/10572250701588657.

[8] C. Walker, 2014. ECM Isn't. Retrieved from http://phigsimc. com/2014/12/11/ ecm-isnt

[9] T.F. Gattiker and D.L. Goodhue, D. L., 2005. What happens after ERP implementation: understanding the impact of interdependence and differentiation on plant-level outcomes, MIS quarterly, Vol. 29(3), pp. 559-585. DOI: $10.2307 / 25148695$ 
[10] S. Shang and P.B. Seddon, 2002. Assessing and managing the benefits of enterprise systems: The business manager's perspective, Information Systems Journal, Vol. 12(4), pp. 271-299. Doi: https:// doi.org/10.1046/j.1365-2575.2002.00132.x.

[11] G. McGovern, 2004. Web Content Management: 10 Predictions for 2004. Retrieved from http://www.marketingprofs.com/4/mcgovern22. asp.

[12] S. Williams, 2000. What is Content Management? Retrieved from http://www.contentmanager.eu.com/history.htm.

[13] E. Long, 2015. The Creation of Content Chaos. Retrieved from http:// community.aiim.org/blogs/emily-long/2015/03/18/solving-sharepointcontent-chaos.

[14] J. Mancini, 2014. Content Management 2020: Thinking Beyond ECM. AIIM Executive Leadership Council. Association for Information and Image Management. Retrieved from https://info.aiim.org/contentmanagement-2020.

[15] B. Boiko, 2005. Content Management Bible, John Wiley \& Sons, Indiana, Canada.

[16] D. Allotey, and G. Ojeabulu, 2011. Potential Benefits Organisations Derive From Using Enterprise Content Management Systems: A Study of Selected Nigerian Organisations. Unpublished Master Thesis, Mälardalen University, Sweden.

[17] M. Befa, E. Kontopoulos, N. Bassiliades, C. Berberidis and I. Vlahavas, 2010. Deploying a semantically-enabled content management system in a state university. In K.N. Andersen, E. Francesconi, A. Gronland, T.M. Van Engers (eds) Electronic Government and the Information Systems Perspective. EGORIS 2010. Lecture Notes in Computer Science, Vol 6267, Springer, Berlin, Heidelberg. Doi: 10.1007/9783-642-15172-9_24. 
[18] J. E. Scott, 2014. The Knowledge Garden and Content Management at JD Edwards J. vom Brocke and A. Simons (eds.), Enterprise Content Management in Information Systems Research, Springer, Berlin Heidelberg. Doi: 10.1007/978-3-642-39715-8_1.

[19] N. Junco, R.A. Bailie and D. Ledet, 2005. A case study of a content management system: Choosing and implementing a CMS. In IEEE International Professional Communication Conference (IPCC), Limerick, pp. 343-345. Doi: http://doi.ieeecomputersociety. org/10.1109/IPCC.2005.1494195

[20] N.I Arshad, R. Bosua, and S.K. Milton, 2012. Exploring the use of enterprise content management systems in different types of Organisations. In $23^{\text {rd }}$ Australasian Conference on Information Systems, Geelong, Victoria, 3-5 December 2012.

[21] T. Paivarinta and B.E. Munkvold, 2005. Enterprise content management: An integrated perspective on information management. In $38^{\text {th }}$ Annual Hawaii International Conference on System Sciences. Doi: 10.1109/HICSS.2005.244

[22] B.E. Munkvold, T. Päivärinta, A.K. Hodne, and E. Stangeland, 2006. Contemporary issues of enterprise content management, Scandinavian Journal of Information Systems, Vol. 18(2), pp. 69-100.

[23] L. Severson, 2014 July. The 'Why' of ECM Failure and the 'How' of ECM Success. Retrieved from http://www.cmswire.com/cms/ information-management/the-why-of-ecm-failure-and-the-how-ofecm-success-025892.php

[24] T.A. Rickenberg, M. Neumann, B. Hohler and M. Breitner, 2012. Enterprise content management-A literature review. AMCIS 2012.

[25] K.R. Grahlmann, C. Hilhorst, S. Van Amerongen, R. Helms and S. Brinkkemper, 2010. Impacts of implementing enterprise content management systems. In $18^{\text {th }}$ European Conference on Information Systems, (ECIS 2010), Pretoria, South Africa, June 7-9, 2010. 
[26] Y. Zhu, Y. Li, W. Wang and J. Chen, 2010. What leads to postimplementation success of ERP? An empirical study of the Chinese retail industry, International Journal of Information Management, Vol. 30(3), pp. 265-276. Doi: 10.1016/j.ijinfomgt.2009.09.007

[27] T.H. Davenport, J.G. Harris and S. Cantrell, 2004. Enterprise systems and ongoing process change, Business Process Management Journal, Vol. 10(1), pp. 16-26. Doi: 10.1108/14637150410518301

[28] R.R. Moeller, 2013. Enterprise Content Management Executive's Guide to IT Governance: Improving Systems Processes with Service Management, COBIT, and ITIL, Wiley Corporate F\&A.

[29] K.K. Hong, and Y.G. Kim, 2002. The critical success factors for ERP implementation: An organisational fit perspective, Information \& Management, Vol. 40(1) pp. 25-40. Doi: 10.1016/S03787206(01)00134-3

[30] P.B. Seddon, C. Calvert and S. Yang, 2010. A multi-project model of key factors affecting organisational benefits from enterprise systems, MIS quarterly, Vol. 34(2) pp. 305-328.

[31] L. Staehr, G. Shanks and P.B. Seddon, 2012. An explanatory framework for achieving business benefits from ERP systems, Journal of the Association for Information Systems, Vol. 13(6), pp. 424-465. Doi: $10.17705 / 1$ jais.00299

[32] S. Nordheim and T. Paivarinta, 2006. Implementing enterprise content management: From evolution through strategy to contradictions outof-the-box, European Journal of Information Systems, Impacts of implementing enterprise content management systems Vol. 15(6), pp. 648-662. Doi: 10.1057/palgrave.ejis.3000647

[33] D. Stewart, 2012. The Real Problem with ECM. Retrieved from http:// blogs.gartner.com/darin-stewart/2012/05/04/the-real-problem-withecm-hint-it-isnt-the-platform/ 
[34] P. Tyrväinen, T. Päivärinta, A. Salminen and J. Iivari, 2006. Characterizing the evolving research on enterprise content management, European Journal of Information Systems, Vol. 15(6), pp. 627-634. Doi: 10.1057/palgrave.ejis.3000648

[35] J .A. Alalwan, M.A. Thomas and H.R. Weistroffer, 2014. Decision support capabilities of enterprise content management systems: An empirical investigation, Decision Support Systems, Vol. 68, pp. 39-48. Doi: $10.1016 /$ j.dss.2014.09.002

[36] B.T. Blair, 2004. An enterprise content management primer, Information Management Journal, Vol. 38(5), pp. 64-66.

[37] R.A. de Carvalho, 2008. An enterprise content management solution based on open source. In: Xu L.D., Tjoa A.M., Chaudhry S.S. (eds) Research and Practical Issues of Enterprise Information Systems II, Springer, Boston, MA. Doi: https://doi.org/10.1007/978-0-387-759029_17

[38] N.L. Junco and R.A. Bailie, 2004. A case study of content management. In International Professional Communication Conference, Minneapolis, MN, USA, 29 Sept.-2 Oct. 2004. Doi: 10.1109/IPCC.2004.1375299.

[39] P. Kostur, 2006. Incorporating Usability into Content Management. In IEEE International Professional Communication Conference, Saratoga Springs, NY, USA, 23-25 Oct. 2006. Doi: 10.1109/IPCC.2006.320384.

[40] H.E. McNay, 2002. Enterprise content management: an overview. In IEEE International Professional Communication Conference, Portland, OR, USA, USA, 20-20 Sept. 2002. Doi: 10.1109/IPCC.2002.1049123.

[41] M.I.M. Salleh, M.R.M. Rosman, R.A.R. Yaacob and Z. Yusoff, 2011. Managing students' electronic disciplinary records via E-merit web content management system. In IEEE Conference on Open Systems, Langkawi, Malaysia, 25-28 Sept. 2011. Doi: 10.1109/ ICOS.2011.6079315. 
[42] M. Nath and A. Arora, 2010. Content management system: Co mparative case study. In IEEE International Conference on Software Engineering and Service Sciences, Beijing, China, 16-18 July 2010. Doi: 10.1109/ICSESS.2010.5552271.

[43] S. Nordheim and T. Päivärinta, 2004. Customization of enterprise content management systems: an exploratory case study. In $37^{\text {th }}$ Annual Hawaii International Conference on System Sciences, Big Island, HI, USA, 5-8 Jan. 2004. Doi: 10.1109/HICSS.2004.1265255.

[44] J.A. Reimer, 2002. Enterprise content management, DatenbankSpektrum, Vol. 2(4), pp. 17-35.

[45] A. Rockley, P. Kostur and S. Manning, 2003. Managing Enterprise Content: A Unified Content Strategy. Indianapolis, Ind: New Riders.

[46] J.E. Scott, 2011. User perceptions of an enterprise content management system. In 44th Hawaii International Conference on System Sciences, Kauai, HI, USA, 4-7 Jan. 2011. Doi: 10.1109/HICSS.2011.473.

[47] C.P. Seeley, 2002. Establishing a business-driven strategy igniting knowledge in your business processes, Knowledge Management Review, Vol. 5(4), pp. 12-15.

[48] H.A. Smith and J.D. McKeen, 2003. Developments in practice VIII: Enterprise content management, The Communications of the Association for Information Systems, Vol. 11(33), pp. 647-659 Doi: 10.17705/1CAIS.01204.

[49] P. Svärd, 2013. Enterprise content management and the records continuum model as strategies for long-term preservation of digital information, Records Management Journal, Vol. 23(3), pp. 159-176. Doi: 10.1108/RMJ-12-2012-0035.

[50] N. Swartz, 2007. Strategic ECM boosts profits. Information Management Journal, July-August, pp. 14. 
[51] J. Vom Brocke, S. Seidel and A. Simons, 2010. Bridging the gap between enterprise content management and creativity: A research framework. In $43^{\text {rd }}$ Hawaii International Conference on System Sciences, Honolulu, HI, USA, 5-8 Jan. 2010. Doi: 10.1109/ HICSS.2010.86.

[52] J. Vom Brocke and A. Simons, 2008. Towards a Process Model for Digital Content Analysis-The Case of Hilti. In BLED 2008 Proceedings, pp. 2.

[53] J. Vom Brocke, A. Simons, C. Sonnenberg, P.L. Agostini and A. Zardini, 2009. Value assessment of enterprise content management systems: A process-oriented approach. In: D'Atri A., Saccà D. (eds) Information Systems: People, Organizations, Institutions, and Technologies. Springer, Heidelberg, Dordrecht, London. Doi: https:// doi.org/10.1007/978-3-7908-2148-2_16.

[54] S. V. Zykov, 2006. Enterprise content management: Theory and engineering for entire lifecycle support. In Proceedings of CSIT 2006, pp. 86-92, Karlsruhe, Germany.

[55] S. V. Zykov, 2009. The integrated methodology for enterprise content management. In $13^{\text {th }}$ World Multi-Conference on Systemics, Cybernetics and Informatics, Orlando, Florida, USA, 10-13 July 2009.

[56] J. Webster and R.T. Watson, 2002. Analyzing the past to prepare for the future: Writing a literature review, Management Information Systems Quarterly, Vol. 26(2). Doi: 10.2307/4132319.

[57] B.G. Glaser and A.L. Strauss, 1967. The Discovery of Grounded Theory: Strategies for Qualitative Research, Aldine Publishing, Chicago. 